\title{
Applicability of Group Discussion as a Pedagogic Practice in a Classroom Setting in Health Education- A Brief Commentary
}

\begin{abstract}
Astha Chaudhry
Department of Oral Medicine and Radiology, Faculty of Dental Sciences and Member Secretary, Internal Quality Assurance Cell (IQAC), SGT University, Gurugram, Haryana, INDIA.
\end{abstract}

Student centered learning (SCL) has brought a paradigm shift in the concept of teaching and learning process from an "Instruction paradigm" to "Learning paradigm". Based on the Andragogic principles of 'selfdirected learning' by Malcolm Knowles ${ }^{1}$ and Blooms taxonomy, ${ }^{2}$ SCL focuses on the constructivism as a theory of learning, wherein the learners construct and reconstruct knowledge in order to learn effectively. SCL happens most effectively when the learning happens as a part of an activity. This brings about a qualitative change in the learner with the development of critical thinking abilities and sense of empowerment. It aims to give the student greater responsibility enabling him to think, process, analyses, synthesise, criticise, apply and solve problems.

Group Discussion (GD) is one such student participatory technique that involves all the students at a given time. It is like a soccer game where the ball synonymous with topic is passed on to each team member for their inputs and the level of sharing of each participant in reaching to goal is achieved through their active participation and contribution.

This pedagogic technique is commonly followed in management schools, social sciences, psychological sciences and journalism where students contribute through their knowledge and opinions and in turn grasps the knowledge and facts shared by fellow group members and the moderator of the group, thus leading to the holistic and overall grasp about a topic.
The pedagogical practices in health education are relatively different than the non-health related specialties. GD in health education sector, primarily in the medical, dental and para-medical sciences is limited to clinicals in the form of case discussions, about the differential diagnosis or the appropriate treatment modality. These case discussions can also be practiced utilizing the problem based approach which involves multiple sessions of group discussions moderated by the facilitator giving key points/hints to reach to the conclusion/ final diagnosis.

The use of Group discussion as a pedagogical practice in a typical classroom setting in health education sector is trivial inspite of it being an extremely stimulating and participatory learning experience. One of the possible reasons is lack of beforehand knowledge and experience in the concerned area. The topics in health education sector are somewhat alienated from the general knowledge and thus thorough understanding of the concept is actually required to initiate and propagate the discussion.

The solution commonly adopted by various institutions is the beforehand distribution of topics and the desired learning material through learning management systems (LMS) or e-lectures and subsequently discussing them in the flipped classroom settings. This enables the learners to gain some base knowledge about the concerned topics and then indulge in various activities or discussions pertaining to same in the classroom setting. These group discussions
Submission Date: 29-06-2020; Revision Date: 04-09-2020; Accepted Date: 25-12-2020

DOI: 10.5530/ijper.55.1s.66 Correspondence: Dr. Astha Chaudhry MDS, Reader, Department of Oral Medicine and Radiology, Faculty of Dental Sciences and Member Secretary, Internal Quality Assurance Cell (IQAC), SGT University, Gurugram-122505, Haryana, INDIA.

Phone no: +919711807733 Email id: dr.asthac@gmail. com

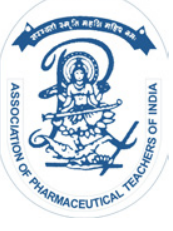

www.ijper.org 
can be termed as "Focused Group Discussions" (FGD) where students discuss about a focused subject topic previously known to them and gradually build up their base knowledge via sharing by fellow students and inputs from the facilitator. The use of FGD in health sector is gaining popularity particularly in the field of health research, ${ }^{3}$ where a small group of participants gather to discuss a specified topic or an issue to generate data.

The 'on spot' distribution of subject topic to facilitate group discussion is relatively uncommon and thought to be impractical in the field of health education particularly in the undergraduate education with an active student strength of 100 or more.

However, the workable solution to make Spot Group Discussion (SGD) applicable in health sciences education set up involves a slightly revised strategy. The students can be asked to bring the desired textbooks to their class. The facilitator can then divide the class into small groups and the desired topic can then be divided into multiple small sub-topics. Each group shall be allotted one sub-topic and students will be asked to read from the reference textbook/ online reading material for a designated time period.

Each group will form a group leader who will jot down the key points pertaining to the subtopic allotted taking inputs from all the group members. The facilitator at this point of time shall monitor each group and give necessary inputs to increase participation of each student and to guide the students towards creating a summary of the subtopic allotted. Once the allocated time is over, the leader of the group then formally describes or summarizes the topic through oral presentation or PowerPoint. The collective presentations by each group would comprehensively cover the entire topic and the facilitator can then finally summarize the entire content filling the gaps leftover by students.
This technique may look impractical or time consuming at first but it is actually engrossing not only for the learners but for the facilitator as well.

The biggest advantage of this pedagogical technique is that there is greater involvement of the learners with maximum retention and learning through peer interaction and through explaining others which is in accordance with the learning pyramid.

The selection of topic and its division into multiple smaller subtopics that are practically doable in the fixed timings of classroom setting is the prime as well as challenging task for the facilitator. Another responsibility for the facilitator in this technique lies in the identification of weaker or non-participating students. The identified students can be made group leaders in subsequent sessions to increase the participation by each candidate.

A limitation of SGD lies in the difficulty in conceptual understanding on reading the topic for the first time in a time constrained classroom setting. However, this can be overcomed by careful selection of the topic by facilitator for practicing SGD. In the author's experience, SGD as a pedagogical practice is extremely effective in revision classes and in the follow-up sessions for topics where basic concept has already been explained by the facilitator.

Thus, the successful execution of GD in health education sector lies in the skills and practices adopted by the facilitator in careful selection of topic, distribution among groups and monitoring and guiding each group.

\section{REFERENCES}

1. Knowles SM, Holton III, Elwood F, Swanson RA. The adult learner: The Definitive Classic in adult education and human resource Development $\left(8^{\text {th }}\right.$ ed.). Burlington, MA Elsevier. 2005. ISBN 0750678372.

2. Huitt W. Bloom et al.'s taxonomy of the cognitive domain. Educational Psychology Interactive. Valdosta, GA: Valdosta State University. 2011. http:// www.edpsycinteractive.org/topics/cognition/bloom.html

3. Wong LP. Focus group discussion: A tool for health and medical research. Singapore Medical Journal. 2008;49(3):256-60. quiz 261.

Cite this article: Chaudhry A. Applicability of Group Discussion as a Pedagogic Practice in a Classroom Setting in Health Education- A Brief Commentary. Indian J of Pharmaceutical Education and Research. 2021;55(1s):s325-s326. 